\title{
QUALIFYING YOUTH FOR THE LABOR MARKET AND MECHANISMS FOR FINANCING YOUTH EMPLOYMENT IN CITIES IN THE MIDDLE EAST AND NORTH AFRICA REGION ... WITH EXPOSURE TO THE EXPERIENCES OF CAIRO AND ALEXANDRIA
}

Mohammed Mahmoud Abdullah Youssef *

Department of Urban Planning Department, College of Urban Planning, Cairo University

\begin{abstract}
Young people hope for tomorrow and makers of the future, and young people are distinguished by tremendous but caged energies looking through to convert that energy into real, tangible production that contributes to pushing the rates of economic, social and political development. Young people in the cities of the Middle East and North Africa region suffer from families of unemployment and poverty that threaten social security and also threaten the path of development of all kinds.

It is the responsibility of the municipalities of cities in the Middle East and North Africa region, the governments and the private sector as well to fulfill their duty towards young people who represent an important qualitative and numerical segment of the population.

And training them and equipping them with the necessary skills required in the labor market, as well as undertaking projects that ensure the employment of young people to ensure their inclusion and make them participate in making their present and future.

During the following chapters, the researcher reviews pictures, programs, and projects to rehabilitate young people for the labor market and employ them in order to present a model or mechanisms that contribute to reducing or eliminating youth unemployment, as well as submitting proposals for activating youth rehabilitation and employment programs.
\end{abstract}

Keywords

LABOR MARKET- FINANCING YOUTH- FINANCING MECHANISMS- CAIRO.

\section{Introduction}

Young people hope for tomorrow and makers of the future, and young people are distinguished by tremendous but caged energies looking through to convert that energy into real, tangible production that contributes to pushing the rates of economic, social and political development. Young people in the cities of the Middle East and North Africa region suffer from families of unemployment and poverty that threaten social security and also threaten the path of development of all kinds.

It is the responsibility of the municipalities of cities in the Middle East and North Africa region, the governments and the private sector as well to fulfill their duty towards young people who represent an important qualitative and numerical segment of the population.

And training them and equipping them with the necessary skills required in the labor market, as well as undertaking projects that ensure the employment of young people to ensure their inclusion and make them participate in making their present and future.

During the following chapters, the researcher reviews pictures, programs, and projects to rehabilitate young people for the labor market and employ them in order to present a model or mechanisms that contribute to reducing or eliminating youth unemployment, as well as submitting proposals for activating youth rehabilitation and employment programs.

Youth unemployment in cities in the Middle East and North Africa region

The cities of the Middle East and North Africa region suffer from high rates of youth unemployment, which represents a real threat to development plans, and this can be illustrated as follows:

1-1 the relative importance of youth

Attempts to define the age group of youth varied in the international reports and the relevant research efforts, some of which raised the age group for youth to extend between 10-24 years, and the last determination

\footnotetext{
* Corresponding author: Mmyoussif@yahoo.com
} 
is the most common by raising the minimum ceiling for the youth age group to be 15 and is now receiving acceptance among international organizations and research bodies.

While recognizing the importance of defining the demographic or age group of youth, because it helps in determining the size of youth and the trends of changing this size It also facilitates national, regional and international comparisons, but it is not sufficient to understand the complex content of this category, as the youth group is not a socially homogeneous group, as it includes a set of variables that influence the youth group and define its characteristics, as it is distributed between adolescents and youth, between males and females, and only Their educational characteristics and their family situation; Class and social class, between upper and middle class, between peasants and workers, between workers and the unemployed, and between students and educated, in addition to specific cultural patterns of life (nomad / rural / urban).

The concepts of youth in different countries reflect a different understanding and consequence of a different diagnosis of the characteristics and conditions of youth, according to the stages and contents of the socio-economic and cultural development of societies.

The concept of youth focuses on the effectiveness of youth as a force of developmental achievement and societal change, and that they have acquired knowledge, information, skills and creative energies distinct from previous generations.

Hence, the concept of youth as a demographic category and a social situation emerged when talking about approaches to discussing youth issues, as this concept includes all of the above determinants, and to which it adds that youth is a demographic and societal complex situation, it means the beginning of self-reliance and freedom from groups - the family - that Depends on it to fulfill its desirable roles socially, which is what some call the transition to maturity.

\section{1-2-Pictures and programs for preparing young people for the labor market}

The labor markets in the private and public sectors in many countries and cities of the MENA region lack a trained manpower that is able - well - to carry out various types of tasks and professional work, and that meets the market's diverse needs for skills and services of various classifications. So that a general education graduate does not need more than a few months to comprehend the work and fully engage in it. The young man graduating from public education - the other - is in urgent need to be accepted within the workforce, so that he finds his place in an institution of government or private institutions, and this cannot be achieved for him unless he has been scientifically and practically qualified in public education with such Serving the labor market and its realistic requirements,

\section{2-1 -Scientific theories about youth training and qualification}

There are many scientific theories that contribute to uncovering many mechanisms and methods of training and qualifying young people to build their career paths that have been addressed by many scholars, researchers and experts in psychology in a number of countries such as Kurt Kewin, Rogers, Super and Roe From the United States of America, Husson and Porot from France, and Jacques Limoges from Canada who adopted the psychoanalytic approach and the approach of social and behavioral psychology, etc. ... Some of them can be examined as follows: (13)

\subsubsection{Holland: "The typologie of vocational behavior."}

Hollande's career choice theory is summarized in that an individual usually chooses a profession that matches his personality lines and fits with his psychological and inner reality, so that his skills are in line with:

\section{1-2 Rogers' theory}

Rogers' theory is based on the fact that every human being is able to develop and improve and overcome his faults and difficulties. This theory applies to the job seeker who suffers from integration difficulties, as he is able, according to Rogers, to overcome the obstacles that hinder his integration and to develop his capabilities, abilities and strengths.

Rogers focused in his theory on the use of individual conversation, especially the counseling conversation, as a discussion centered on the customer, and this conversation takes place within the framework of the relationship of help and aims to understand the individual's problem in its real context in connection with the reality of the pension and its own characteristics in order to help him in personal development And social acclimatization.

\section{1-3 Jacques Limoges' theory Limoges'}

theory is based on an example containing 6 phases between the "Le modèle du trèfle chanceux" career path, each of which is called "The Employablity State".

\section{2-2 Youth Training Mechanisms and Programs}

Young people can be trained and qualified in many places, whether through formal education (as part of the curriculum), job training institutions, business incubation centers, small and medium enterprise 
development agencies or industrial organizations, and training can include all applicants or target special groups such as the new unemployed. Or long unemployed. In some cases, financial aid can be provided to students to support their participation in the program in the form of a small sum of money paid to them at the beginning or as periodic subsidies.

\section{3-Mechanisms for financing youth project employment}

There are many types of financing projects for rehabilitation, training and employment of youth in cities in the MENA region, and this can be explained as follows (22):

\section{3-1 public finance}

It means the narrow meaning that the burden of managing it falls on the state's general budget and does not include financing the public business sector, and public finance stems in the budget from the main sovereign sources, which are taxes, fees and the transferred public sector surplus.

\section{3-2 private finance}

Private financing often comes from savings in the family sector or the informal sector.

\section{3-3 sequence finance}

The origin was government funding by making tenders for the implementation of works in the new areas, and modern methods have been adopted that reduce the burden on the state's general budget, and in some cases the government guarantees the achievement of a certain surplus.

\section{4- The experience of Cairo and Alexandria in preparing youth for the job market}

The phenomenon of youth unemployment in Egypt is one of the most important challenges facing the Egyptian economy at the current stage, in addition to the accumulated balance of the unemployed, the number of new entrants to the labor market is about 600 thousand individuals annually, in addition to the concentration of this problem among young people in the age group From 15 to 29 years old, especially among those with intermediate, upper-intermediate and university degrees, and the matter does not stop with the foregoing, as the new global variables, mainly the liberalization of markets, intensifying competition, and the expansion in the use of information technology, pose more challenges to society's ability to face with that problem.

\section{6- Recommendations for activating youth rehabilitation and employment programs}

By reviewing the various youth rehabilitation programs previously mentioned in the second chapter, and through the Egyptian experience in qualifying young people for the labor market and employing them, the researcher proposes a number of recommendations to activate the programs and policies of cities in the Middle East and North Africa region aimed at youth in order to rehabilitate and employ them. These recommendations are as follows:

4-6-1 Linking university education to the needs of the labor market and conducting training courses for young people immediately before their graduation to familiarize them with the labor market, its dimensions and how to enter it.

4-6-2 The importance of official bodies joining forces to agree on unified programs to qualify and train young people for the labor market, and that a part of at least $20 \%$ of the general budget is allocated annually for the training and employment of youth.

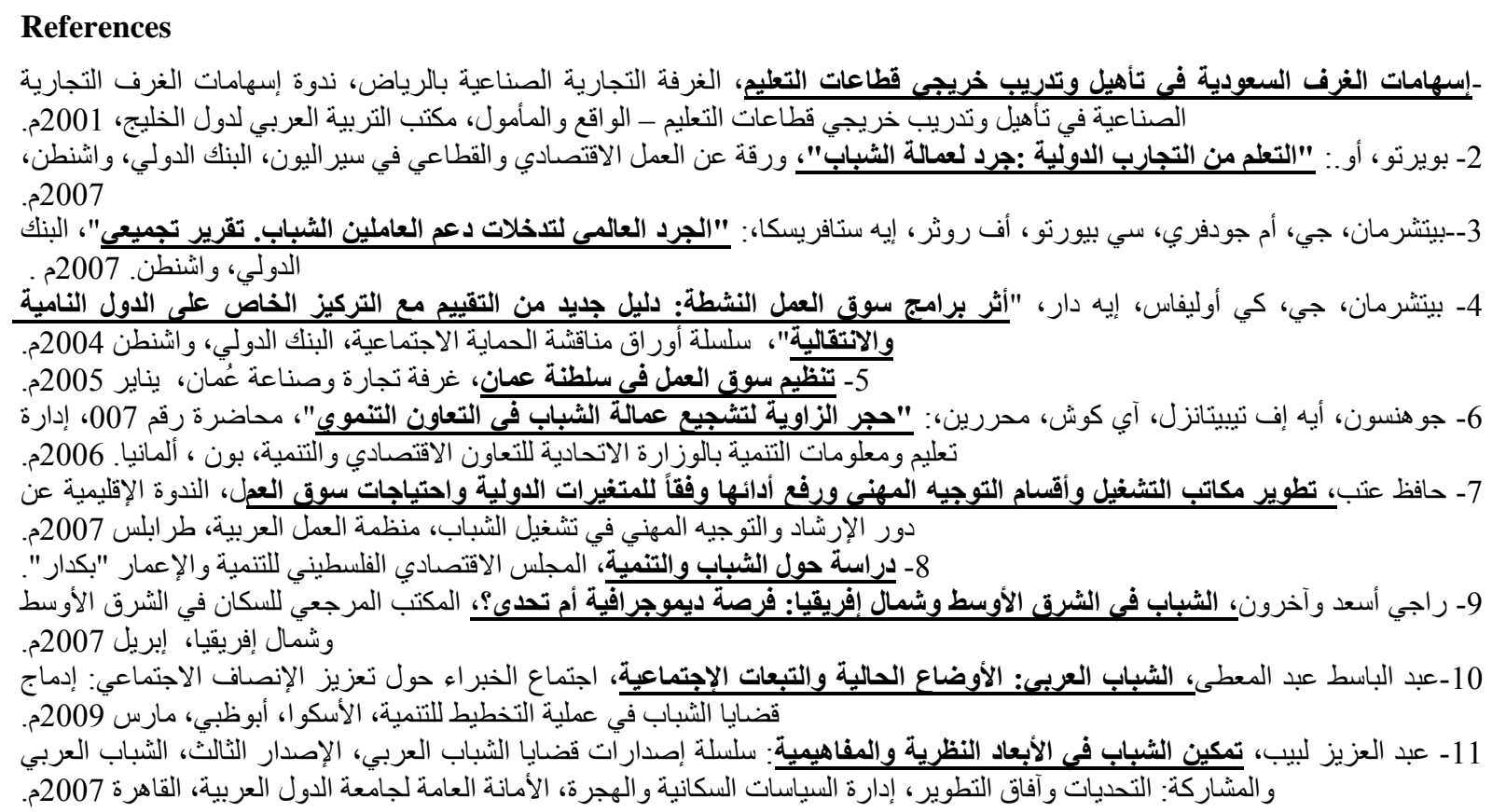


12 - محمد صبري الثافعي، التدريب المهنى والتعليم الفنى فى جمهورية مصر العربية، المؤتمر الثاني لتنمية الموارد البشرية و التدريب، منظمة التربة

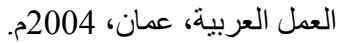

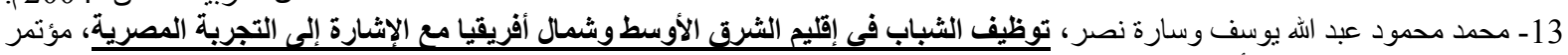

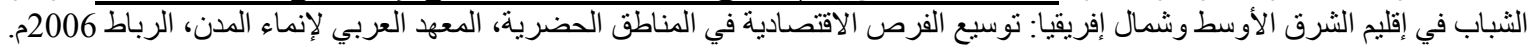

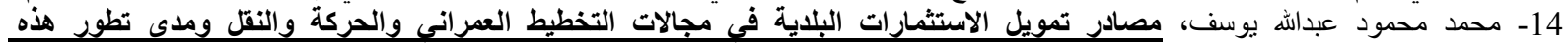

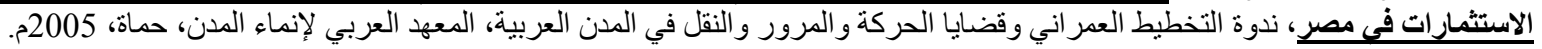

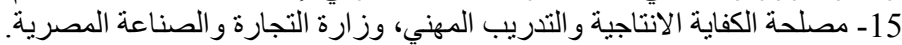

16http://www.alshabab.gov.eg/ar_index.aspx

17- Nader Kabbani and Ekta Kathari, "A Situation Analysis of Youth Employment in the MENA Region," presented at the conference on Urban Children and Youth in the MENA Region: Addressing Priorities in Education, held in Dubai, May 16-18, 2005.

18- Ragui Assaad, "Unemployment and Youth Insertion in the Labor Marketin Egypt," Egyptian Center for Economic Studies (ECES) Working Paper.2007

19-United Nations, Millennium Development Goals Report 2006 (New York-4:United Nations, 2006)

20-World Bank, MENA Development Report: Gender and Development in the Middle East and North Africa (Washington, DC: World Bank, 2004)

21 World Bank, Unlocking the Employment Potential in the Middle East and North Africa: Toward a New Social Contract (Washington, DC: World Bank, 2004).

Received: February 15, 2018

Accepted: April 20, 2018 